\title{
Reuse of Synthetic Plastic Fibres and Plastic Granules in Concrete
}

${ }^{\text {"1 }}$ Gonnade E. M., ${ }^{2}$ Joshi S. V., ${ }^{3}$ Kulkarni P. B. ${ }^{4}$ Tiwari M. S.

1,2,3,4 Civil Engineering Department, Shri Ramdeobaba College of Engineering and Management, Nagpur-13

Email: gonnadeem@rknec.edu, joshisv@rknec.edu,kulkarnipb@rknec.edu, tiwarims@rknec.edu

\author{
Received: 14th November 2019, Accepted: 31st January 2020, Published: 29th February 2020
}

\begin{abstract}
The use of plastic is considerably increased in day-to-day life for supply of the materials, liquids, foods and other essentials daily products. These single use plastic is disposed off in very disorderly manner. Therefore, the disposal of plastic waste becomes a universal problem because of it is non-biodegradable, and availability of plastic waste in huge quantity in the various countries having considerable population. This plastic waste can be reduced by utilizing in the same or in other forms in day-to-day various activities and development of infrastructure like cement concrete roads, pavements and other low cost housing schemes, but it is realize that all the plastic waste material cannot be reutilized. Its partial utilization may also become the solution to reduce the impact on the environment and ecological problems. The cost of ingredient concrete materials is continuously increasing due to non availability, taxation, transportation and also the wastes of materials. Therefore, the plastic waste can be converted into synthetic fibres and granules and can be utilize in concrete as a partial replacement of sand. The main objective of this laboratory investigation is to reduce the impact of plastic waste on the environment by utilizing in infrastructure development. For laboratory investigation, synthetic fibres $1 \%, 2 \%$ and $3 \%$ of dry weight of sand is utilized to replace the sand and plastic granules $5 \%$, $10 \%$ and $15 \%$ of dry weight of sand is utilized to replace the sand. The strength parameters of concrete are tested in the laboratory such as compressive strength, tensile strength and workability of concrete. The test result shows positive impact of utilization of plastic waste up to some extent.
\end{abstract}

\section{Keywords}

Waste Plastic, Synthetic Plastic Fibres, Plastic Granules, Strength and Concrete

\section{Introduction}

This research laboratory investigation was conducted to study the impact of other forms of plastic waste on the characteristic strength of concrete. The plastic synthetic fibres and plastic granules are produce by using mainly E-plastic waste and thick plastic waste to be processed and crushed in different ways. The preliminary characteristic of concrete without and with granules and fibres was studied. The size of the granules is considered as the size of sand.[3] The PET bottles after caring out the required processing can be utilized to reuse in concrete composition. Electronic waste generated form computer hard wares, TV and other electronics and electrical appliances at the end of its useful life. Due to vast use of electrical and electronic appliances in the developed and developing countries there is a huge production of E-waste, because of use and throw policy. It is essential to develop certain methodology to reuse and dispose off plastic waste in safe hygienic ways to reduce soil, water and air pollution for the sustainable development. [6]

\section{Production of Plastic Waste}

The plastic waste are mainly classified as peruse plastics and post waste plastics. During the production of various items based on plastic materials has not meet the required design specification or cutting waste, defected and rejected materials comes under the category of perused plastic, while drinking water bottles, plastic utensils, household waste etc may be suitable for recycling and reuse. Very thin thickness packaging materials films, shopping bags, rubbish bags etc. may come under the category of post waste plastic. Plastic fibres made up of different polymer types like cable sheathing, strapping and other related products are considered as flexible plastic.

\section{Utilization of Plastic Waste}

In recent study of 2014, it is reported that the use of plastic in India is as follows:

1. PET bottles/Jars : $16 \%$

2. HDPE natural bottles: $4.9 \%$

3. Bags wraps: $29.4 \%$

4. Others plastic containers: $12.9 \%$

5. Other plastic in packaging industries $36.8 \%$

It is also reported that the plastic consumption in India is about $4 \mathrm{~kg}$ on the other hand average plastic consumption world wise is about $25 \mathrm{~kg}$. [7] 


\section{Disposal and Reuse}

Before recycling most of the plastic are sorted according to their resin type, polymers type and colors. Few processes for disposal are; Thermal depolymerisation, Heat compression, Distributed Recycling, Land Filling, Incineration, Blast furnace, Gasification, Deriving fuel (petrol, diesel, LPG) from Plastic. [4]

\section{Materials and Methods}

The aim of this research work is to observe the change in the characteristics of concrete when different proportions of fibres and granular plastics are added in replacement of fine aggregates, i.e. sand. Therefore the laboratory investigations were carried out on synthetic plastic fibres and plastic granules for the proper utilization in the construction industry.

The detail laboratory investigation includes the following:

Preliminary investigation of concrete and concrete materials.

- To study the strength of plain cement concrete such as compressive and tensile strength.

- To check the workability of concrete in the form of slump values of concrete when different samples of plastics are added as compared to plain cement concrete.

- To study the effects on strength of concrete when different proportions of fibres plastic is added as a replacement for sand.

- To study the effects on strength of concrete when different proportions of granular plastic is added as a replacement for sand.

In the laboratory, before mixing, casting and testing of the concrete, the primary properties of the cement were determined as per IS code provision. The preliminary testing of ingredient material of concrete were fineness, consistency, initial and final setting time of cement, water absorption of coarse aggregate, impact value test of coarse aggregate and specific gravity of coarse aggregate.[8]

\section{Mix Combination}

For laboratory investigation, various concrete mix combinations for M15 grade of concrete were studied.

I. Plane cement concrete

II. Plane cement concrete + plastic fibres $(1 \%, 2 \%$ and $3 \%$ of dry weight of sand)

III. Plane cement concrete + plastic granules $(5 \%, 10 \%$ and $15 \%$ of dry weight of sand)

Combination I and II is utilized for determination of strength of concrete as compressive and tensile, while combination III is utilized for determination of compressive strength only.[5]

The mixing, casting and testing of concrete was done as per the IS456 (2000) [1] and IS10262. The plastic fibres (dimensions: $30 \mathrm{~mm}$ length, $2 \mathrm{~mm}$ wide and $0.5 \mathrm{~mm}$ thick) and plastic granules (diameter $5 \mathrm{~mm}$ ) as shown in fig. 1was used in the laboratory investigation. The strength of concrete was observed for 7 day and 28 days. The material like ordinary Portland cement, synthetic plastic fibres and plastic granules is procured from the local market. [2]

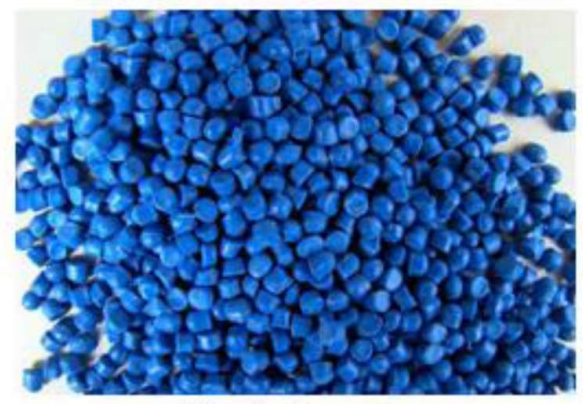

Plastic Granules $5 \mathrm{~mm} \Phi$

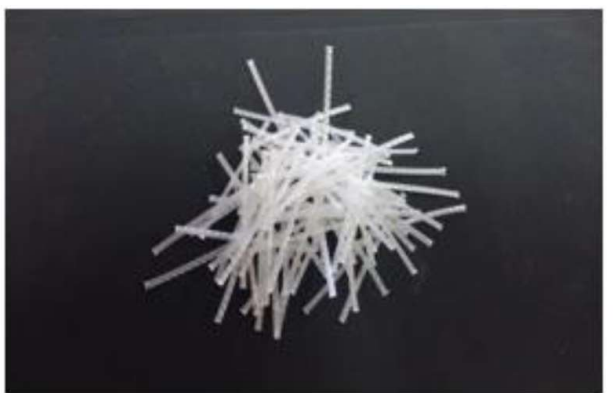

Virgin Plastic Fibres $\mathrm{L}: 30 \mathrm{~mm}$ B: $2 \mathrm{~mm}$ T: $0.5 \mathrm{~mm}$

Fig. 1: Plastic Granules and Plastic Fibres Used in Laboratory Investigation 
Observations and Results Analysis

Test results observed in laboratory investigation are represented graphically in fig. 2, 3 and 4.
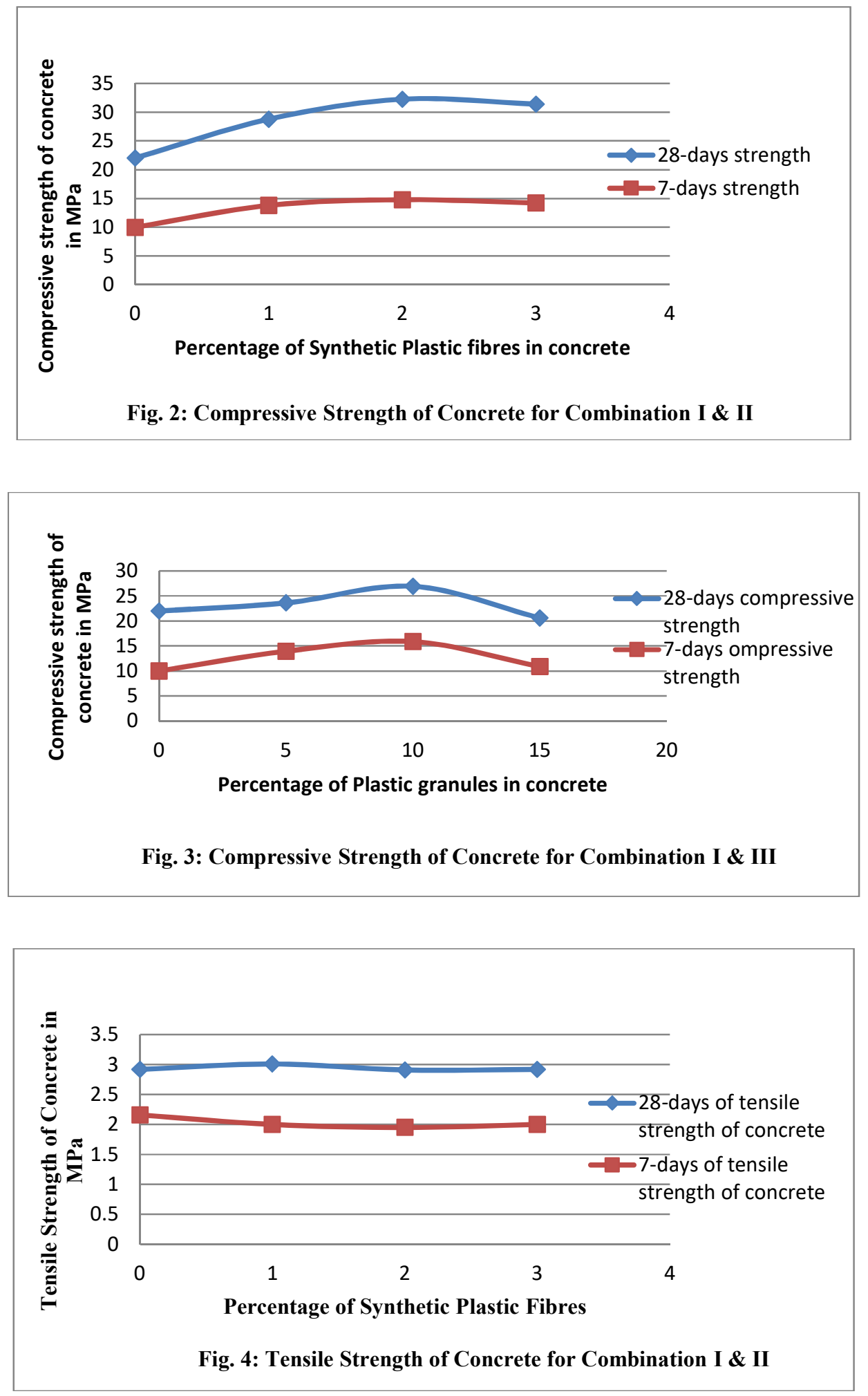

In figure 2, It was observed that, by increasing the percentage of synthetic plastic fibres in concrete up to $2 \%$, then 7 day and 28 day compressive strength of concrete also increases. But compressive strength decreases beyond $2 \%$. Hence optimum is 2 percent. 
It was also observed from figure 3 that, by increasing the percentage of plastic granules in concrete upto $10 \%$, then 7 day and 28 day compressive strength of concrete also increases. But compressive strength decreases beyond $10 \%$.

In figure 4 , It was observed that, by increasing the percentage of synthetic plastic fibres in concrete up to $3 \%$, then 7 day and 28 day tensile strength of concrete remains almost constant or gradually decreases.

\section{Conclusion}

On the basis of laboratory investigations and results analysis for the use of plastic synthetic fibres and plastic granules to replace the fine aggregate are concluded as follows:

1. The universal problem of disposal of plastic waste is taken care by using the plastic wastes in concrete for the substitute of sand which ultimately save the consumption of sand and vis-à-vis minimize environmental pollution due to plastic waste.

2. Reuse of plastic waste in the form of synthetic plastic fibres in concrete improves the compressive and tensile strength of concrete up to $2 \%$ and beyond $2 \%$ the strength of concrete is slightly decreased.

3. Reuse of plastic waste in the form of plastic granules in concrete improves the compressive of concrete up to $10 \%$ and beyond $10 \%$ the concrete strength is slightly decreased.

4. It is also observed that the due to utilization of plastic synthetic fibres and plastic granules in concrete, the workability of concrete is slightly decreased and accordingly the slum values were reduced.

\section{References}

1. IS 456 (2000), "Testing of plain cement concrete"

2. IS 10262 (2009), "Guidelines for "concrete mix design"

3. K. Sasikumar, S. G. Krishna, "Solid Waste Management”, published by PHI learning

4. Rafat Siddique, Jamal Khatib, Inderpreet Kaur, "Use of recycled plastic in concrete: A review", Waste management 28, 2008 pp 1835-1852

5. Shetty M. S “ A test book on Concrete Technology”, Published by S. Chand, Faridabad

6. Engineering Properties of Concrete with Waste Recycled Plastic: A Review Adewumi John Babafemi, Branko Šavija , Suvash Chandra Paul and Vivi, Journal on Sustainability 2018, 10, 3875.

7. Development of recycled Polypropylene plastic fibers to reinforce concrete, PhD thesis, Yin Shi, James Cook University, 2015

8. Use of different forms of waste plastic in concrete - A Review, R Sharma, P P Bansal, Journal of Cleaner Production, 2016

9. Mechanical Properties of Concrete Contain Waste Fibers of Plastic Straps, Hadeel R. Khatab, Samaher J. Mohammed and Laith A. Hameed, HYPERLINK "https://iopscience.iop.org/journal/1757-899X" IOP Conference Series: Materials Science and Engineering, HYPERLINK "https://iopscience.iop.org/volume/1757$899 \mathrm{X} / 557 "$ Volume 557 